\title{
Review: the Ottawa knee rule accurately rules out knee fractures and can substantially reduce the need for $x$ rays in patients with acute knee injuries
}

Bachmann LM, Haberzeth S, Steurer J, et al. The accuracy of the Ottawa knee rule to rule out knee fractures: a systematic review. Ann Intern Med 2004;140:121-4.

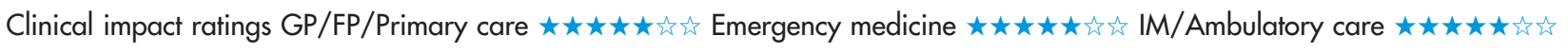
In patients with acute knee injuries, is the Ottawa knee rule (OKR) accurate for ruling out knee fractures?

\section{METHODS}

\begin{tabular}{|c|c|}
\hline 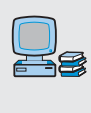 & $\begin{array}{l}\text { Data sources: Medline and PreMedline (1966 to January 2003), } \\
\text { CINAHL (1982-2003), EMBASE/Excerpta Medica (1980- } \\
\text { 2003), Biosis (1990-2003), the Cochrane Library (2002), and } \\
\text { the Science Citation Index database; reference lists; and experts. }\end{array}$ \\
\hline & $\begin{array}{l}\text { Study selection and assessment: studies in any language that } \\
\text { assessed the OKR, investigated fractures confirmed } \\
\text { radiographically or in combination with follow up; and reported } \\
\text { enough information to calculate sensitivity, specificity, and } \\
\text { likelihood ratios. Study quality was ranked as high quality (level } \\
1=\text { consecutive patient enrolment, reference standard test done } \\
\text { on all patients, radiographic assessment of fracture done blinded } \\
\text { to the results of the OKR); intermediate quality (level } 2=\text { met } 2 \text { of } \\
\text { the } 3 \text { level } 1 \text { criteria); low quality (level } 3=\text { met } 1 \text { of the level } 1 \\
\text { criteria); or very low quality (level } 4=\text { met none of the level } 1 \\
\text { criteria). }\end{array}$ \\
\hline \begin{tabular}{|l|}
1 \\
2 \\
0 \\
0 \\
0 \\
\end{tabular} & Outcomes: sensitivities, specificities, and likelihood ratios. \\
\hline
\end{tabular}

\section{MAIN RESULTS}

11 studies met the selection criteria. Of 4929 adult patients in the 6 studies that were pooled for a meta-analysis, 5 patients $(0.12 \%)$ had a false negative result on the OKR test (ie, a missed fracture not detected by the rule). The table shows the pooled test characteristics of the OKR. At a knee fracture prevalence of 7\%, the probability of a fracture after a negative assessment using the OKR was $0.37 \%$ (CI 0.15 to 1.48 ). The OKR's moderate specificity implies a potential $50 \%$ reduction in the need for ordering $x$ rays.

For correspondence: $\operatorname{Dr} \dddot{L} \dddot{M}$ Bachmann, Zurich University, Zurich Switzerland. lucas.bachmann@evimed.ch

Source of funding: no external funding

\section{CONCLUSION}

In adult patients with acute knee injuries, the Ottawa knee rule is accurate for ruling out knee fractures and can substantially reduce the need for radiography.

\section{Commentary}

Cinicicion linical decision rules are important to emergency physicians because they help consolidate the most discriminating aspects of the clinical assessment in a valid instrument that can then drive decision making. The OKR's ability to determine which patients are in need of a radiograph so that a fracture will not be missed was already largely established by validation studies published in the mid to late 1990s. ${ }^{12}$ The same holds true for the OKR's utility (specificity) in reducing the rate at which radiographs would be ordered in the emergency department. A controlled implementation study confirmed its beneficial impact in the clinical setting, ${ }^{2}$ thus the OKR can be considered a level 1 clinical decision rule based on a commonly used hierarchy. ${ }^{3}$ As level 1 evidence, the OKR is an accurate decision rule that can change clinician behaviour and improve outcomes.

The review by Bachmann et al strengthens our appreciation of the accuracy of the OKR by establishing a strong negative likelihood ratio as reported from a number of high quality validation trials.

Systematic reviews of diagnostic instruments are expected to narrow the degree of certainty around point estimates of test performance, and the analysis adopted by Bachmann et al produced confidence intervals slightly narrower than those reported in the individual validation trials included in the meta-analysis. ${ }^{12}$ The authors of this review argue for the need to pursue further research in defining the accuracy of the OKR, but an even more important challenge might be to determine how to best improve the uptake of this validated decision rule in the clinical setting. Eddy S Lang, MDCM SMBD Jewish General Hospital, McGill University Montréal, Québec, Canada

1 Stiell IG, Greenberg GH, Wells GA, et al. Prospective validation of a decision rule for the use of radiography in acute knee injuries. JAMA 1996;275:611-5.

2 Stiell IG, Wells GA, Hoag RH, et al. Implementation of the Ottawa Knee Rule for the use of radiography in acute knee injuries. JAMA 1997;278:2075-9.

3 McGinn T, Guyatt G, Wyer P, et al. Diagnosis. Clinical prediction rules. In: Guyatt G, Rennie D (editors). Users' guides to the medical literature. Chicago: AMA Press, 2000.

Accuracy of the Ottawa Knee Rule for ruling out knee fractures in adult patients with acute knee injury (6 pooled studies)*

\begin{tabular}{llll}
\hline Sensitivity (95\% Cl) & Specificity (Cl) & + LR & - LR \\
\hline $98.5 \%(93$ to 100$)$ & $49 \%(43$ to 51$)$ & 1.93 & 0.05 \\
\hline${ }^{*} \mathrm{Cl}$ and $\mathrm{LRs}$ defined in glossary. Weighted mean sensitivities and specificities were calculated and bootstrapped; \\
- LRs were pooled by using a bootstrap procedure.
\end{tabular}

